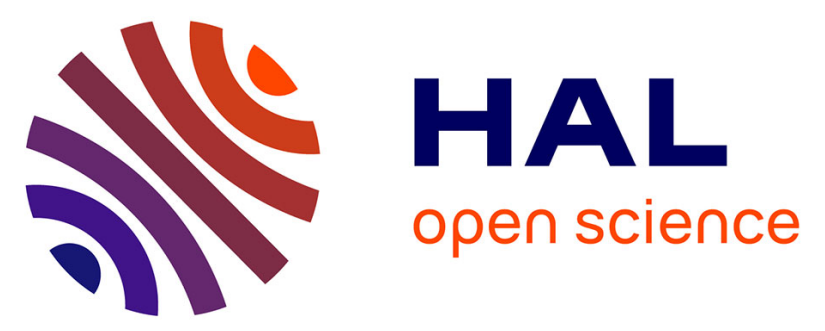

\title{
Synthesis of Platinum Nanoparticles by Plasma Sputtering onto Glycerol: Effect of Argon Pressure on Their Physicochemical Properties
}

Vanessa Orozco-Montes, Amael Caillard, Pascal Brault, William

Chamorro-Coral, Janick Bigarre, Audrey Sauldubois, Pascal Andreazza, Stéphane Cuynet, Steve Baranton, Christophe Coutanceau

\section{To cite this version:}

Vanessa Orozco-Montes, Amael Caillard, Pascal Brault, William Chamorro-Coral, Janick Bigarre, et al.. Synthesis of Platinum Nanoparticles by Plasma Sputtering onto Glycerol: Effect of Argon Pressure on Their Physicochemical Properties. Journal of Physical Chemistry C, 2021, 125 (5), pp.3169-3179. 10.1021/acs.jpcc.0c09746 . hal-03157543

\section{HAL Id: hal-03157543 https://hal.science/hal-03157543}

Submitted on 15 Mar 2021

HAL is a multi-disciplinary open access archive for the deposit and dissemination of scientific research documents, whether they are published or not. The documents may come from teaching and research institutions in France or abroad, or from public or private research centers.
L'archive ouverte pluridisciplinaire HAL, est destinée au dépôt et à la diffusion de documents scientifiques de niveau recherche, publiés ou non, émanant des établissements d'enseignement et de recherche français ou étrangers, des laboratoires publics ou privés. 


\title{
Synthesis of platinum nanoparticles by plasma sputtering onto glycerol: effect of the argon pressure on their physicochemical properties
}

\author{
V. Orozco-Montes ${ }^{1}$, A. Caillard ${ }^{1}$, P. Brault ${ }^{1}$, W. Chamorro-Coral ${ }^{1}$, J. Bigarre ${ }^{2}$, A. Sauldubois ${ }^{3}$, P.

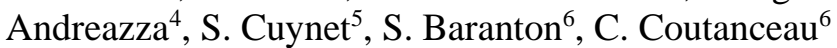 \\ ${ }^{1}$ GREMI, Université d'Orléans, CNRS, 14 rue d'Issoudun, BP6744, 45067 Orléans cedex 2, France \\ ${ }^{2}$ CEA DAM, Le Ripault, 37260 Monts, France \\ ${ }^{3}$ CME, Université d'Orléans, 45067 Orléans cedex 2, France \\ ${ }^{4}$ ICMN, Université d'Orléans, CNRS, 1 b rue de la Férollerie, 45071 Orléans cedex 2, France \\ ${ }^{5}$ IJL, Université de Lorraine, CNRS, 2 allée André Guinier, F-54000 Nancy, France \\ ${ }^{6}$ IC2MP, Université de Poitiers, CNRS, 4 rue Michel Brunet, TSA 51106, 86073 Poitiers cedex 9, France
}




\begin{abstract}
:
Platinum nanoparticles (Pt NPs) were synthesized in glycerol as liquid substrate via a magnetron sputtering method at different argon pressures (1.0, 4.0 and 9.0 Pa). Then, Pt NPs were deposited onto a Vulcan XC72 powder to form carbon supported Pt NPs catalysts. Molecular Dynamic (MD) simulations were carried out using parameters mimicking the deposition conditions of Pt in plasma sputtering experiments to determine key parameters for the growth of Pt NP and to understand the growth mechanism at the atomic scale. MD simulations showed that Pt NP growth depended on the kinetic energy of Pt atoms arriving onto the liquid substrate, which is related to the argon (Ar) pressure. The Pt NPs obtained for different Ar pressures and dispersed in glycerol were characterized by small-angle X-ray scattering (SAXS) to investigate the Ar pressure effect on Pt NPs size. Independently on the Ar pressure, SAXS results revealed the presence of two NPs populations. The first population is composed of isolated small NPs with an average diameter increasing from 1.8 to $3.2 \mathrm{~nm}$ with the pressure. Transmission electron microscopy (TEM) analysis performed on carbon supported Pt NPs (Pt NPs/C) displayed the same diameter evolution, but the Pt NPs diameters were found slightly larger (from 2.5 to $3.7 \mathrm{~nm}$ ) than those obtained by SAXS in glycerol. Both SAXS and TEM measurement revealed a second population of larger nano-objects that could correspond to agglomerates of individual small NPs from the first population formed either during the deposition in the liquid bulk or more probably at the liquid surface. The electrochemical behavior of the Pt NPs/C catalysts was studied in a conventional three-electrode electrochemical cell at room temperature in $\mathrm{N}_{2}$-saturated 0.50 mol L-1 $\mathrm{H}_{2} \mathrm{SO}_{4}$ electrolyte. It was shown that the Pt NPs size increased with the argon pressure, which further led to a decrease of the Pt electrochemical surface area (ECSA).
\end{abstract}




\section{INTRODUCTION.}

Electrochemical energy conversion devices, such as polymer electrolyte membrane fuel cells (PEMFCs) and PEM electrolyzers are considered as possible candidates for integration in future renewable energy network $^{1,2}$. However, the oxygen reduction reaction (ORR) kinetic at the cathode of a PEMFC is slow and the overpotential at the cathode is generally high (higher than $0.200 \mathrm{~V}$ ), whereas that of the hydrogen oxidation at the anode is ca. $0.050 \mathrm{~V}^{3}$. For this purpose, platinum $(\mathrm{Pt})$ or its alloys are often required as electrocatalyst because of their excellent catalytic activity for the $\mathrm{ORR}^{4}$. Electrocatalysis involves surface reactions, therefore, a high surface/inner atoms ratio is desirable to improve the Pt nanoparticles (Pt NPs) performance. NPs with size ranging between 2 to $4 \mathrm{~nm}$ are generally preferred ${ }^{5}$.

NPs can be obtained through various physical, chemical or physicochemical routes ${ }^{6,7}$. The chemical methods are very versatile in terms of controlling NPs shape and size by varying the reaction conditions. However, NPs chemical synthesis requires additives, which generate by-products difficult to remove and NPs with limited purity. In contrast, physical methods (such as sputtering, thermal evaporation, laser ablation, spark discharge...) on solid substrates avoid the use of additives, allowing the production of pure metallic NPs with the same material composition as that of the starting material. Moreover, these methods can be considered as green approaches using non-toxic reducing agents and avoiding the formation of byproducts 8.

Among physical techniques for preparing electrocatalytic NPs, magnetron sputtering is known to produce efficient Pt NPs deposited on a microporous carbon layer ${ }^{9}$ or on a polymer electrolyte membrane ${ }^{10}$ to directly fabricate the catalytic layer composite. However, using the sputtering method for the deposition of metal NPs onto such substrates often makes the control of the NPs properties (size, dispersion and morphology) complex. Moreover, this process makes also difficult to create three phase boundaries by the addition of ionomer in comparison with the conventional liquid ink preparation techniques based on classical chemical processes for carbon supported NPs. A solution consists in synthesizing NPs directly in a liquid phase using magnetron sputtering technique and to disseminate the NPs onto a porous substrate. This innovative method 
takes advantages of liquids with an extremely low vapor pressure, capable to sustain vacuum processing and to stabilize the NPs generated by magnetron sputtering ${ }^{11}$. Ionic liquids (ILs) ${ }^{12}$ are the most used liquid because of their extremely low vapor pressure (for example $10^{-10} \mathrm{~Pa}$ at $298 \mathrm{~K}$ for the $\mathrm{IL}_{\left[\mathrm{C}_{4} \mathrm{mim}\right]}\left[\mathrm{PF}_{6}\right]^{13}$ ), and to a lesser extent organic and vegetable oils ${ }^{14}\left(0.192 \mathrm{kPa}\right.$ at $299.1 \mathrm{~K}$ for castor oil $\left.{ }^{15}\right)$. But the synthesis of highly dispersed small NPs with a narrow size distribution remains a challenge and thin film could also appear on the liquid surface as a function of the deposition parameters (working distance between the target and the liquid substrate, sputtering time, temperature of the target, applied voltage, discharge current and gas pressure, etc.). For instance, Wender $e t a l^{16}$ revealed that the formation of Ag NPs or Ag thin films depended on the applied voltages and on the surface coordination ability of the different vegetable oils. Lower discharges voltages and/or lower surface coordination abilities led to the formation of a film at the surface of the liquid, while the opposite led to the formation of NPs. Hatakeyama et $l^{17}$ studied the effect of different sputtering conditions on Au NPs synthesis onto an IL. It was shown that both, the target temperature and the applied voltage had a strong influence on the Au NPs size, while the working distance between the target and the surface of the IL, the sputtering time and the discharge current had few or no influence.

Therefore, sputtering deposition parameters play an important role and determine the size distribution of NPs synthesized in a liquid medium. Another advantage of this deposition method is that the dispersed NPs inside the liquid can be extracted, and then dispersed onto a high surface area carbon support used in fuel cell electrodes. For the last 10 years, Torimoto and Kuwabata groups fabricated Pt nanocatalysts supported on carbon using sputtering technique onto IL ${ }^{18-20}$. K. Yoshii et al. ${ }^{18}$ fabricated Pt NPs supported on different carbon materials, i.e. single walled carbon nanotubes (SWCNT) and carbon black (Vulcan XC- 72), by adding these carbon materials directly in the IL after the Pt NP growth. In their study, Pt NPs were homogeneously dispersed on the carbon support displaying a mean particle diameter of $3.6-3.7 \mathrm{~nm}$ and an electrochemical surface area (ECSA) between 51.4 and $63.1 \mathrm{~m}^{2} \cdot \mathrm{g}^{-1}$. Even if this preparation method is powerful when using ILs that can be easily manipulated under ultra-high vacuum, such liquids are highly complex to synthesize and purify, and hence are expensive. However, fuel cells require large amounts of 
catalytic powder containing an expensive metal $(\mathrm{Pt})$, therefore a preparation method of lower cost is preferred. Other authors proposed to use liquid polyethylene glycol (PEG) instead of ILs ${ }^{21}$ and succeeded to synthesize Pt NPs with a $2 \mathrm{~nm}$ mean diameter without surfactant ${ }^{22}$. The carbon supported NPs exhibited an ECSA of $45.9 \mathrm{~m}^{2} \mathrm{~g}_{\mathrm{Pt}}^{-1}$ as measured by CO stripping. The authors observed no or very few agglomerations. Similar results were obtained by Deng et $\mathrm{al}^{23}$.

In the present study, we propose to use an alternative inexpensive liquid, glycerol, as liquid medium to synthesize Pt nanocatalyst by an eco-friendly and economic method. Glycerol is a by-product of biodiesel production to an extent of $10 \mathrm{wt} \%$, and is therefore considered as a waste by the biofuel industries. Its relatively high vapor pressure $\left(\sim 0.1 \mathrm{~Pa}\right.$ at $\left.298 \mathrm{~K}^{24}\right)$ compared to IL could modify the properties of the $\mathrm{Pt}$ NPs synthesized and optimum deposition parameters have to be defined. For example, the influence of the argon pressure in the plasma chamber should influence the formation of either Pt NPs and/or Pt thin films. This influence is studied and discussed here. To better understand the Pt growth phenomena at the atomic scale, Molecular Dynamic (MD) simulations are carried out reproducing the deposition conditions of plasma sputtering experiments. Small-angle X-ray scattering (SAXS) experiments are performed to estimate the Pt NPs average size in the glycerol medium. Three carbon-supported Pt NPs electrocatalytic powders (Pt NPs/C) were prepared by adding a carbon black powder (Vulcan XC 72) to the glycerol medium containing the Pt NPs synthesized under different argon pressures (1.0, 4.0 and 9.0 Pa) and filtrating the slurry. Size distributions in the electrocatalytic powders and the atomic arrangement of Pt NPs are investigated using Transmission Electron Microscopy (TEM) and High-Resolution Transmission Electron Microscopy (HRTEM), respectively. Finally, Pt NPs/C catalysts are tested in an electrochemical cell to evaluate their electroactive surface area.

\section{EXPERIMENTAL SECTION}

\subsection{Synthesis procedure}


The synthesis of Pt NPs is performed in a high vacuum apparatus pumped by turbomolecular and primary pumps allowing achieving a limit vacuum of $2 \cdot 10^{-4} \mathrm{~Pa}$. The lower limit of the pressure is increased to $5.10^{-}$ ${ }^{3} \mathrm{~Pa}$ when the cylindrical glass vial (24 mm inside diameter and $30 \mathrm{~mm}$ height) containing $4 \mathrm{~cm}^{3}$ of glycerol (Sigma Aldrich, ReagentPlus ${ }^{\circledR}$, purity $\geq 99.0 \%$ ) is placed on a movable substrate holder at room temperature. The viscosity of glycerol is measured at room temperature $\left(25^{\circ} \mathrm{C}\right)$ using a rotational coaxial cylinder viscometer. The glycerol is placed between two concentric cylinders. One cylinder rotates with a constant angular velocity $(75 \mathrm{rpm})$, while the other cylinder is suspended to a torsion wire. After the driven cylinder starts to rest, the suspended cylinder rotates until an equilibrium position is reached, where the force due to the torsion wire is just balanced by the viscous force transmitted through the liquid. Thus, the measured viscosity of glycerol at $25{ }^{\circ} \mathrm{C}$ is ca. 0.60 Pa.s. The vapor pressure and the density of the glycerol at $25{ }^{\circ} \mathrm{C}$ are $\sim 0.10 \mathrm{~Pa}$ and $1.26 \mathrm{~g} \mathrm{~cm}^{-3}$, respectively ${ }^{19}$.

The 2 inches in diameter, balanced magnetron (equipped with a $2 \mathrm{~mm}$ thick Pt target) is powered by a DC power supply (pinnacle plus Advanced Energy) and faces the liquid surface at a $120 \mathrm{~mm}$ distance. After 2 hours pumping (to reach the base pressure of $5 \cdot 10^{-3} \mathrm{~Pa}$ ), argon (Alphagaz 1 from Air Liquide, purity of $99.99 \%$ ) is introduced in the chamber with a flow rate of $40 \mathrm{sccm}$ (standard cubic centimeter per minute) and the working pressure is adjusted by partially closing a valve in front of the turbomolecular pump. Before Pt deposition, the Pt target surface is cleaned by sputtering Pt atoms for $5 \mathrm{~min}$ at a DC power of $100 \mathrm{~W}$; a shutter is placed between the liquid surface and the target. After opening the shutter, the Pt target is sputtered for $20 \mathrm{~min}$ at a constant power of $100 \mathrm{~W}$. The argon working pressure was adjusted to 1.0, 4.0 and 9.0 $\mathrm{Pa}$ for the deposition inducing a modification of the cathode voltage (490, 430 and $380 \mathrm{~V}$, respectively). In order to estimate the mass of Pt arriving onto the glycerol surface, the glass vial is retracted and a quartz microbalance (6 MHz quartz with an Au electrode) is positioned at the same distance from the target as that for the liquid surface (120 $\mathrm{mm}$ in the axis of the Pt target). The deposition rates given by the quartz microbalance are equal to 60,50 and $29 \mu \mathrm{g} \cdot \mathrm{cm}^{-2} \cdot \mathrm{min}^{-1}$ for argon working pressures of 1.0, 4.0 and 9.0 $\mathrm{Pa}$, respectively, and they remain constant over the time scale of 20 min. Assuming a constant sticking 
coefficient on the glycerol surface, the masses of Pt deposited are equal to $3.0 \mathrm{mg}, 2.5 \mathrm{mg}$ and $1.5 \mathrm{mg}$ in the glass vial (2.54 $\mathrm{cm}^{2}$ opening area) containing $4 \mathrm{~cm}^{3}$ glycerol.

\subsection{Molecular dynamics simulation for Pt NP growth}

The deposition of Pt atoms onto glycerol is simulated using Molecular Dynamics (MD) to understand which deposition parameters influence the formation of the floating thin film. Indeed, MD is able to simulate phenomena at the nanoscale when all interaction potentials (force fields) between involved species are available $\mathrm{e}^{25-28}$. To simulate the Ar pressure variations, the mean kinetic energy of the Pt atoms arriving onto the glycerol is modified. Values of $2 \mathrm{eV}$ and $0.039 \mathrm{eV}$ are chosen for pressures of 1.0 and $9.0 \mathrm{~Pa}$, respectively. These values are obtained using a modified Thompson formula ${ }^{29,30}$ for an atom travelling through a plasma over a defined target to substrate distance. It has been experimentally observed using a thermocouple immersed into the glycerol that the liquid temperature is increased during the $20 \mathrm{~min}$ deposition from $293 \mathrm{~K}$ to about $310 \mathrm{~K}$. The temperature increase by ca. $17 \mathrm{~K}$ appears low considering the DC power of $100 \mathrm{~W}$ and the distance of $12 \mathrm{~cm}$ but it indicates clearly that the plasma induces a transfer of energy onto the liquid surface. This heating originates from the sputtered species arriving onto the liquid surface, from all other species formed in the plasma (ions, radicals, electrons, etc.), from eventual chemical reactions taking place in the plasma and from infrared radiation emitted by the target. The temperature on the liquid surface could be probably much higher that the value measured by the thermocouple in the liquid bulk. For MD simulation the energy released by the Pt atoms and absorbed by the glycerol molecules should lead to an increase of the local temperature. During deposition, the extreme surface of the liquid where Pt species are deposited constitutes an off-equilibrium system and viscous heating is inevitable. The heat could be extracted using some thermostat devices surrounding the glass wall of the liquid container, which is not possible due to the large volume of container, or by the molecules of the liquid (solution that we adopted). Before the injection of Pt atoms, every MD simulation run was started after an equilibration period at 300 K using a Nosé-Hoover thermostat. Then, during the deposition of Pt atoms, the use of a local Langevin thermostat with a dumping time of $100 \mathrm{fs}$ was chosen, allowing dissipating the energy coming from the 
sputtered atoms or produced by the formation of NPs on the spatially localized scale. A reactive force field for modelling Pt, C, H, O interactions (interactions between $\mathrm{Pt}$ and glycerol) ${ }^{31}$ is used. $400 \mathrm{Pt}$ atoms are released towards a glycerol $\left(\mathrm{C}_{3} \mathrm{H}_{8} \mathrm{O}_{3}\right)$ slab of $7 \times 7 \times 10 \mathrm{~nm}^{3}$ with a density of $1.26 \mathrm{g.cm}$. . A simulation lasts for $0.16 \mathrm{~ns}$ and the timestep is $0.1 \mathrm{fs}$ for allowing $\mathrm{H}$ fast motion. The $\mathrm{Pt}$ atoms are released during the first $0.08 \mathrm{~ns}$, one after each other every $0.2 \mathrm{ps}$. Additional $0.08 \mathrm{~ns}$ simulations are carried out for allowing the system to relax down to $300 \mathrm{~K}$. So, a full run lasts for $0.16 \mathrm{~ns}$, i.e. $1.610^{6}$ timesteps.

\subsection{Characterization of as-synthesized Pt NPs by SAXS}

Pt NPs obtained for the three Argon working pressures (1.0, 4.0 and 9.0 Pa) are characterized using SAXS experiments $^{32-34}$ to determine the influence of the argon pressure on the Pt NPs mean size. SAXS is a very powerful tool for investigating in situ NPs without manipulating or destroying the samples. The technique helps to have a better understanding of the NPs properties, but also of the direct self-assembly of (monoand multimetallic) $\mathrm{NPs}^{35}$. SAXS characterization has been mostly employed for exploring the properties of NPs prepared in ILs, PEG oil or even in glycerin diluted in ethanol ${ }^{36}$ after the deposition or during thermal post treatment ${ }^{37-40}$. SAXS measurements are carried out using the laboratory platform based on a XENOCS system. The beam generated by an $\mathrm{x}$-ray generator $(30 \mathrm{~W}, \mathrm{Cu}$ anode with $\lambda=0.154 \mathrm{~nm})$ is collimated (Xray spot size of $500 \mu \mathrm{m}$ ) using two scatterless single crystal slits whereas the scattering signals is collected by a two-dimensional detector (Pilatus $300 \mathrm{~K}, 83.8 \times 106.5 \mathrm{~mm}^{2}$ ) at a distance of $570 \mathrm{~mm}$ from the $2 \mathrm{~mm}$ in diameter capillary (0.01 mm wall) containing the Pt NPs based solution. Considering the sample-detector distance and the detector size, the scattering vector $(q=4 \pi \sin \theta / \lambda$, where $\theta$ is the scattering angle) ranges from 0.01 to $9.00 \mathrm{~nm}^{-1}$ (the detector is not centered on the beam). Just before SAXS measurement, homogenization of the glycerol suspension is realized by ultrasound irradiation for $5 \mathrm{~min}$, then the suspension is diluted with ethanol in a 1:2 ratio to decrease the viscosity of the mixture and to allow its introduction in a glass capillary using a syringe. The capillary is sealed and installed on a high precision XY stage in the SAXS vacuum chamber (pressure of ca. $10 \mathrm{~Pa}$ ). The scattering signal is obtained after signal 
normalization by subtracting the signal obtained for a capillary containing the glycerol/ethanol (1:2) mixture without NPs to eliminate contribution from parasitic background (slits, windows, capillary, etc.).

\subsection{Preparation of Pt NPs/C catalytic powders}

Carbon black (Vulcan XC-72 heat-treated at $400^{\circ} \mathrm{C}$ under $\mathrm{N}_{2}$ for 4 hours) is added to the glycerol solution to transfer most of the Pt NPs on carbon support. The amount of carbon is calculated to obtain a nominal metal/carbon weight ratio of $30 \mathrm{wt} . \%$ (assuming that all nanoparticles are deposited on the substrate). Then glycerol is removed by vacuum filtration through a commercial alumina oxide membrane purchased from Sigma Aldrich (pore size of $0.2 \mu \mathrm{m}$, thickness of $0.1 \mathrm{~mm}$, and diameter of $13 \mathrm{~mm}$ ). The resulting retentate is washed several times with hot ultrapure water and acetone to remove the remaining glycerol. The Pt NPs/C powder is then dried at $70{ }^{\circ} \mathrm{C}$ in an oven overnight. Fig. 1 gives an overview of the procedure required to obtain the Pt NPs/C powder.

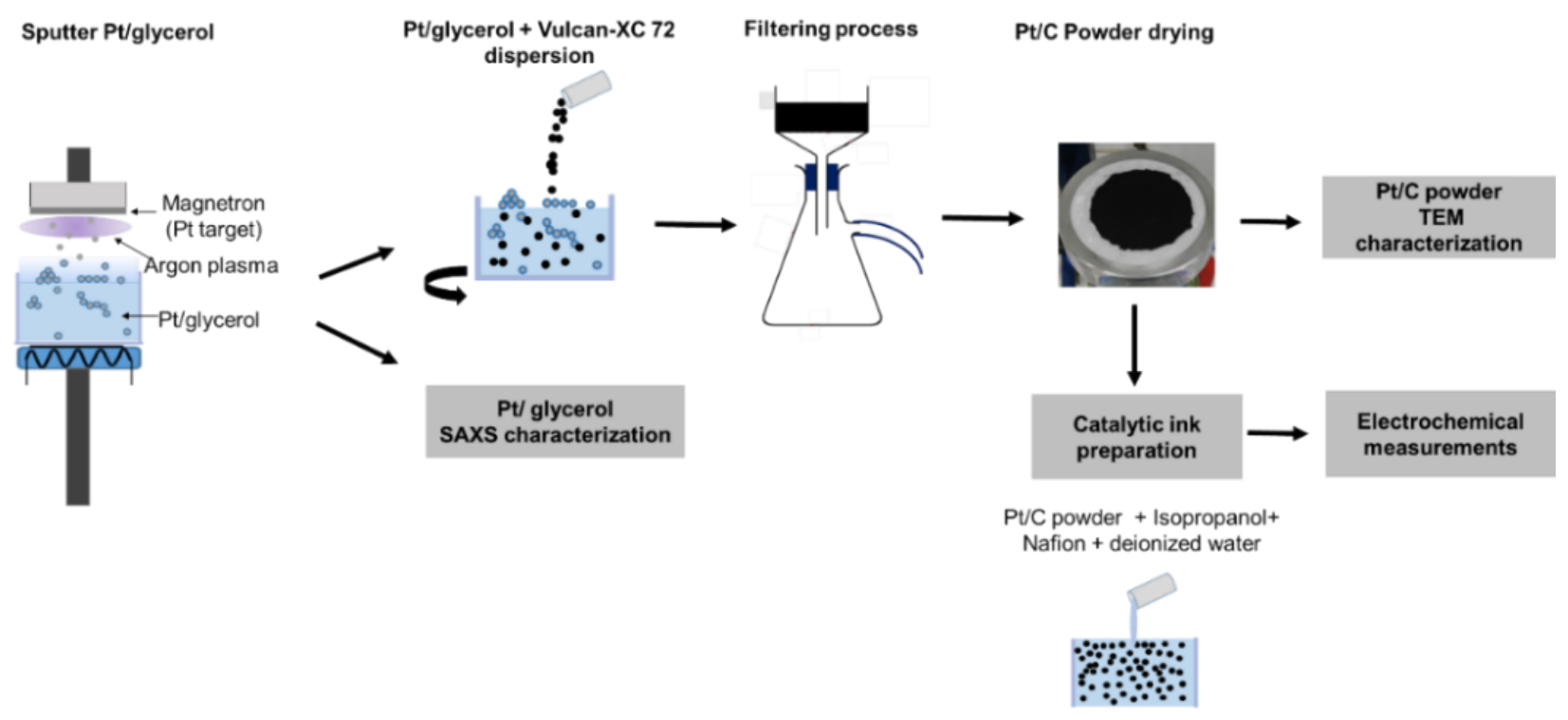

Figure 1. Schematic of the Pt NPs/C catalyst preparation procedure.

\subsection{Characterization of Pt NPs/C by TEM and HRTEM}

Pt NPs deposited on a carbon substrate are investigated using an aberration corrected HRTEM equipped with a Cold Field Emission Gun (ACCELARM 200F JEOL) operating at $200 \mathrm{kV}$. The six TEM samples 
are prepared by dropping the Pt NPs/C catalytic powder dispersed in isopropanol on a copper grid covered by an amorphous carbon thin layer (SPI Supplies carbon coated 200 mesh copper grids $3 \mathrm{~mm}$ ). Grids are dried at room temperature before TEM observations. HRTEM images are obtained due to double spherical aberration correction of both condenser and objective lens until fifth and third order, respectively, giving a $\mathrm{C}_{\mathrm{s}}$ value of $-0.1 \mathrm{~mm}$. The magnification used for HRTEM is $2 \mathrm{Mx}$ and images are acquired by a CMOS OneView using a time exposure of $0.6 \mathrm{~s}$.

\subsection{Electrode preparation and electrochemical characterization of Pt NPs/C}

Catalyst inks are prepared from the six Pt NPs/C powders by ultrasonically dispersing $2 \mathrm{mg}$ of the Pt NPs/C powder in $0.3 \mathrm{~mL}$ of ultrapure water (18.2 $\mathrm{M} \Omega$, milliQ from Millipore) and $40 \mu \mathrm{L}$ of Nafion solution (5 wt\% Nafion ${ }^{\circledR}$ perfluorinated resin solution in aliphatic alcohols from Aldrich). For electrochemical measurements, the working electrodes are prepared by dispersing a drop of the catalyst ink on a glassy carbon disc $\left(0.071 \mathrm{~cm}^{-2}\right.$ geometric surface area) to obtain a metal loading of $100 \mu \mathrm{g}_{\text {metal }} \mathrm{cm}^{-2}$.

Electrochemical measurements are carried out in a classical three-electrode electrochemical cell fitted with a glassy carbon counter-electrode $\left(3 \mathrm{~cm}^{2}\right.$ geometric surface area) and a reversible hydrogen electrode (RHE), using a VersaSTAT 4 potentiostat/galvanostat (Princeton Applied Research, Ametek). All working electrodes are immersed in $\mathrm{N}_{2}$-purged $0.50 \mathrm{~mol} \mathrm{~L}^{-1} \mathrm{H}_{2} \mathrm{SO}_{4}$ (ACS reagent, purity 95.0-98.0\% from SigmaAldrich) aqueous electrolyte and a constant potential of $0.100 \mathrm{~V}$ vs. RHE is applied for $15 \mathrm{~s}$ before 14 cyclic voltammograms are recorded between 0.100 and $1.450 \mathrm{~V}$ vs. RHE at $0.050 \mathrm{~V} \mathrm{~s}^{-1}$. All CVs reported herein correspond to the last stable cycle and all potentials values are referred to RHE.

\section{RESULTS AND DISCUSSION}

Fig. 2 shows the top view of the glass vial after the Pt deposition at each pressure. At 1.0 Pa (Fig. 2a), a homogeneous black solution is obtained together with a floating thin film $(f T F)$ covering partly the glycerol surface. For higher Ar pressures, 4.0 $\mathrm{Pa}$ and 9.0 Pa, the formation of the $f T F$ at the glycerol surface is greatly enhanced covering almost the whole glycerol surface (Figs. 2b and 2c). Moreover, the glycerol seems to be 
colorless after the plasma sputtering experiment performed at 9.0 Pa. The as-prepared samples obtained from these deposition conditions are denoted $1 P a_{-} w / \_f T F, 4 P a \_w / \_f T F$ and $9 P a \_w / f T F$ (the first number corresponding to the pressure value in $\mathrm{Pa}$ and $w / f F T$ to with floating thin film). A second set of three samples was performed under the same conditions for which the floating thin films have been removed just after the plasma sputtering experiments. The removed Pt flakes are washed, dried and weighed. The remaining Pt masses in the glass vials after the removal of the floating thin films are estimated by subtraction to $2.1,1.9$ and $0.6 \mathrm{mg}$ for plasma deposition at 1.0, 4.0 and 9.0 $\mathrm{Pa}$, respectively. These samples are denoted $1 P a \_w / o \_f T F, 4 P a_{-} w / o_{-} f T F$ and $9 P a \_w / o \_f T F$ (the first number corresponding the pressure value in $\mathrm{Pa}$ and w/o_fFT to without floating thin film).

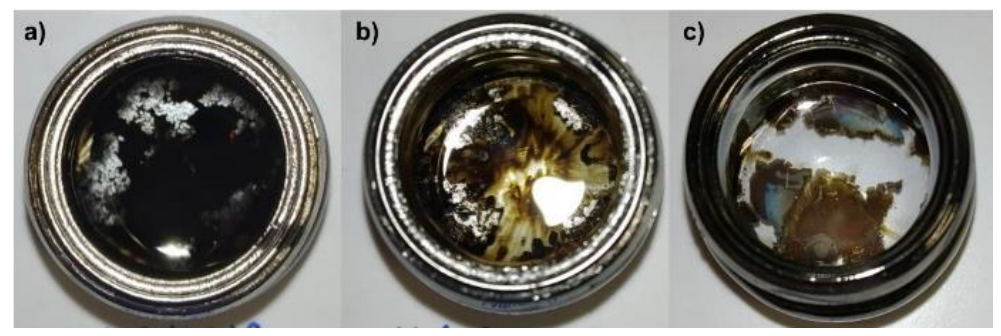

Figure 2. Top view of the glass vials containing $4 \mathrm{~cm}^{3}$ of glycerol immediately after the Pt deposition performed at three different Argon pressures: (a) 1.0 Pa, (b) 4.0 $\mathrm{Pa}$ and (c) $9.0 \mathrm{~Pa}$.

MD simulation snapshots obtained for 1.0 $\mathrm{Pa}$ and $9.0 \mathrm{~Pa}$ at $293 \mathrm{~K}$ are displayed in Figs. 3a and 3c. In both cases, most of the Pt atoms are in the shallow depth of $5 \mathrm{~nm}$ from the glycerol surface forming a continuous film. At 1.0 Pa (Fig. 3a), the Pt atoms diffuse within the first $5 \mathrm{~nm}$ depth of the liquid phase, whereas at 9.0 Pa (Fig. 3c) few Pt atoms diffuse towards the glycerol bulk and most of Pt atoms form agglomerates at the glycerol surface ${ }^{41}$. The diffusion of Pt atoms towards the glycerol bulk seems to be avoided at 9.0 Pa. It was previously shown that a higher pressure, 9.0 $\mathrm{Pa}$ in our case, induced a lower kinetic energy forcing the $\mathrm{Pt}$ atoms to a lateral motion regime at the liquid surface favoring a quasi-two-dimensional growth process ${ }^{29}$. This prevision from MD simulations is totally consistent with the experimental findings in Fig. 2 showing the formation of a more covering floating Pt thin films at the glycerol surface when the argon pressure is increased from 1.0 Pa to 9.0 Pa. Fig. 3b and Fig. 3d show the changes in temperature (associated with the 
kinetic energy) and in potential energy of the Pt atoms for both sputtering pressures, every points of the curves being determined over a timestep of $0.16 \mathrm{~ns}$. The decrease of the Pt atom temperature clearly indicates that the Pt atoms progressively transfer their energy to the glycerol molecules thermostatically fixed at $293 \mathrm{~K}$.
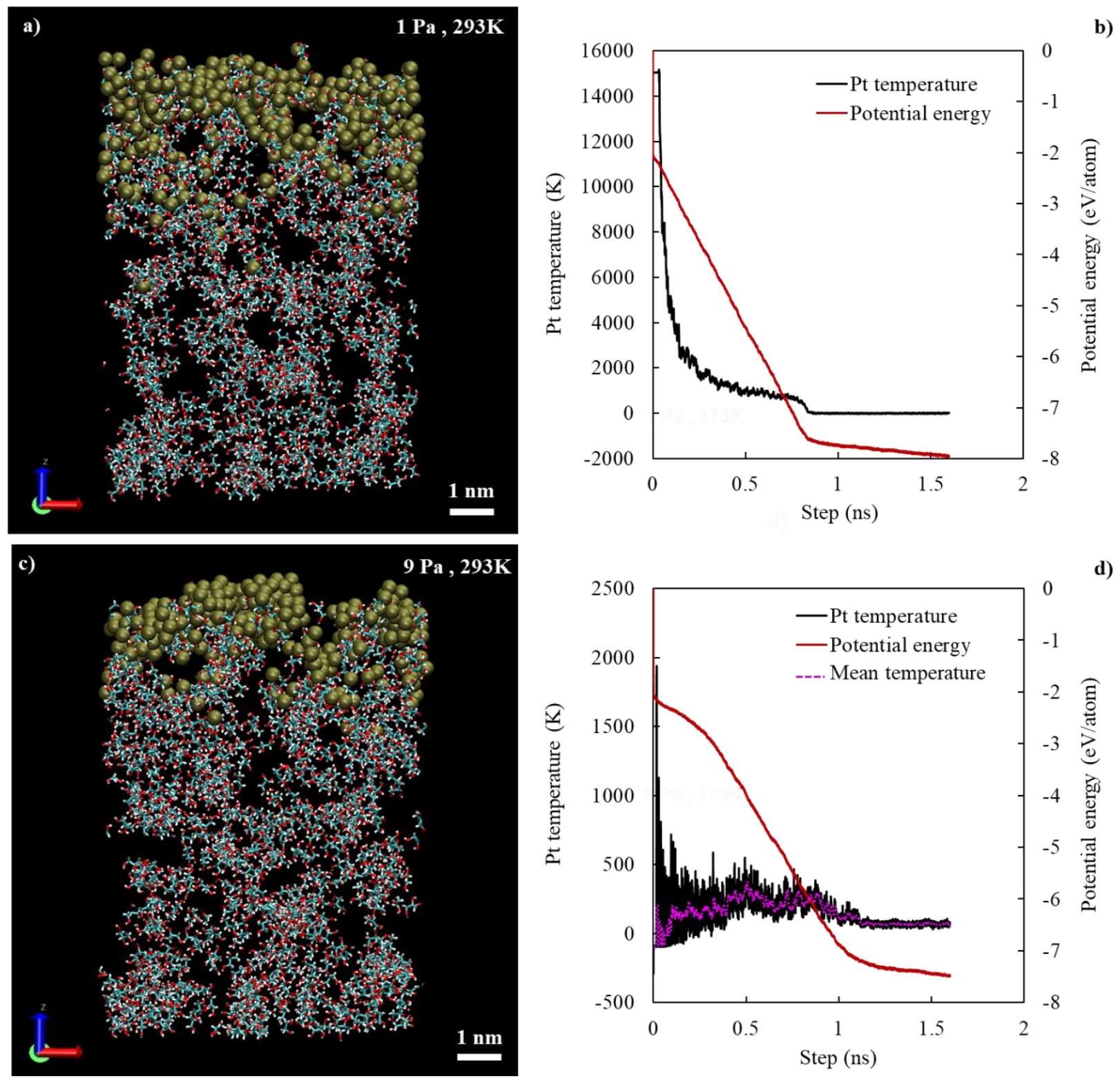

Figure 3. Right: snapshot of molecular dynamic simulation of $\mathrm{Pt}$ atoms deposited on glycerol for (a) $1 \mathrm{~Pa}$ and (c) $9 \mathrm{~Pa}$. Pt atoms are green, $\mathrm{C}$ atoms are white, $\mathrm{H}$ atoms are blue and $\mathrm{O}$ atoms are red.

Left: changes with time of the average Pt temperature and the average potential energy per Pt atom for (b) $1 \mathrm{~Pa}$ and (d) $9 \mathrm{~Pa}$. 
In addition, the potential energy per Pt atom rapidly decreases during a first period and then slowly decreases during a second one due to clusters formation and agglomeration. At 1.0 $\mathrm{Pa}$, the transition between these periods corresponds to an inflection point occurring at $\mathrm{t}=0.8 \mathrm{~ns}$, which corresponds to the end of the injection period of Pt atoms. During the first period, the potential energy decreases much faster at $1.0 \mathrm{~Pa}$ than at 9.0 Pa indicating that the Pt-Pt bond formation is accelerated for high kinetic energy. At 9.0 Pa, the transition between both periods occurs at $0.12 \mathrm{~ns}$, i.e. at a time much higher than that of $0.08 \mathrm{~ns}$ observed at 1.0 Pa. This delay is an indication that the diffusion time of Pt atoms on the surface before sticking to another $\mathrm{Pt}$ atom is increased at 9.0 $\mathrm{Pa}$. On the other hand, $100 \%$ of the injected $\mathrm{Pt}$ atoms are collected onto the glycerol substrate at $1.0 \mathrm{~Pa}$ while only $95 \%$ are collected at 9.0 Pa. This means that due to a low kinetic energy some Pt atoms are not able to find a suitable deposition site at 9.0 Pa. The simulation boxes and the timescale values used in the present work allow giving an insight on the influence of the argon pressure on the formation of Pt $\mathrm{fTF}$, but not on the Pt NPs growth inside the glycerol medium due to the small amount of $\mathrm{Pt}$ atoms penetrating the liquid.

Figure 4 displays the SAXS signals in the q range from 0 and $4 \mathrm{~nm}^{-1}$ after data post-treatment by subtraction of the signal obtained without NPs for the six Pt deposits dispersed in glycerol/ethanol mixture. All SAXS measurements represented as function of the scattering vector (q) display a first intense signal for $\mathrm{q}<1 \mathrm{~nm}^{-}$ ${ }^{1}$ and second signal between 1 and $4 \mathrm{~nm}^{-1}$ corresponding to two families of nano-objects characterized by two different mean sizes. Whereas the fit of the SAXS patterns could not be obtained accurately using a classical log-normal equation (not shown), the experimental measurements can be nicely fitted above $1 \mathrm{~nm}^{-}$ ${ }^{1}$ by a theoretical scattering curve assuming a Gaussian distribution and a full sphere model characterized by a frequency of particles $\mathrm{N}_{1}$, a mean diameter $\mathrm{D}_{1}$ and a diameter standard deviation $\sigma_{1}$ typical of the objects in population 1 . The experimental signal below $1 \mathrm{~nm}^{-1}$ could be more coarsely approximated by using a second distribution function of particles with spherical shape characterized by a mean diameter $\mathrm{D}_{2}\left(\right.$ with $\mathrm{D}_{1}$ $<\mathrm{D}_{2}$ ), a frequency $\mathrm{N}_{2}$ (with $\mathrm{N}_{1}>\mathrm{N}_{2}$ ) and a diameter standard deviation $\sigma_{2}$ for the nano-objects in population 2. The distance of $570 \mathrm{~mm}$ between the capillary and the detector is not sufficient to carefully study the 
change in $\mathrm{D}_{2}$ with the applied pressure for the sputtering experiments, which ranges between 5 and $8 \mathrm{~nm}$ with $\mathrm{N}_{2}$ inferior to $1 \%$ and only the value of $\mathrm{D}_{1}$ and $\sigma_{1}$ will be discussed hereafter.

The high intensity of the SAXS signal below $0.8 \mathrm{~nm}^{-1}$ clearly indicates the presence of large nano-objects (population 2), whereas the scattering tails between 0.8 and $3 \mathrm{~nm}^{-1}$ comes from the presence of smaller ones (population 1). For each figure, the lines represent the theoretical scattering signals coming from the population 1 composed of spherical NPs with a dispersion $\sigma_{1} / \mathrm{D}_{1}$ of $15 \%$. This ratio has been adjusted to properly fit both experimental signals obtained for $1 \mathrm{~Pa}$ (a) and has been considered unchanged for higher pressures. When the floating thin films are removed $\left(w / o_{-} f T F\right)$, all experimental curves can be adjusted between 1 and $4 \mathrm{~nm}^{-1}$ by the theoretical scattering curves and the mean diameter of the Pt NPs (population 1) can be deduced. These mean diameters are equal to $2.1( \pm 0.05)$ and $2.6( \pm 0.1) \mathrm{nm}$ for working pressures of 1.0 and 4.0, respectively. At 9.0 $\mathrm{Pa}$, the SAXS signal being too low to determine accurately the size of population 1, the mean value of $3.2 \mathrm{~nm}$ is accompanied with the high uncertainty of $\pm 0.5 \mathrm{~nm}$. This result indicates that the size of Pt NPs increases with the argon pressure which is commonly observed on solid substrate $^{27}$ and has already been pointed out for Ag NPs synthesized in silicone oil ${ }^{43,44}$. When the floating thin films are not removed $(w / f T F)$, only the sample obtained for 1.0 Pa give enough signal to be fitted and a mean diameter of $1.8 \pm 0.05 \mathrm{~nm}$ is obtained. Surprisingly, this value is lower than the one obtained for the same pressure without the $f T F\left(w / o_{-} f T F\right)$. Table 1 gives the diameter of the population $1 \mathrm{D}_{1}$ for the 6 samples deduced from the analysis of the SAXS signal. 

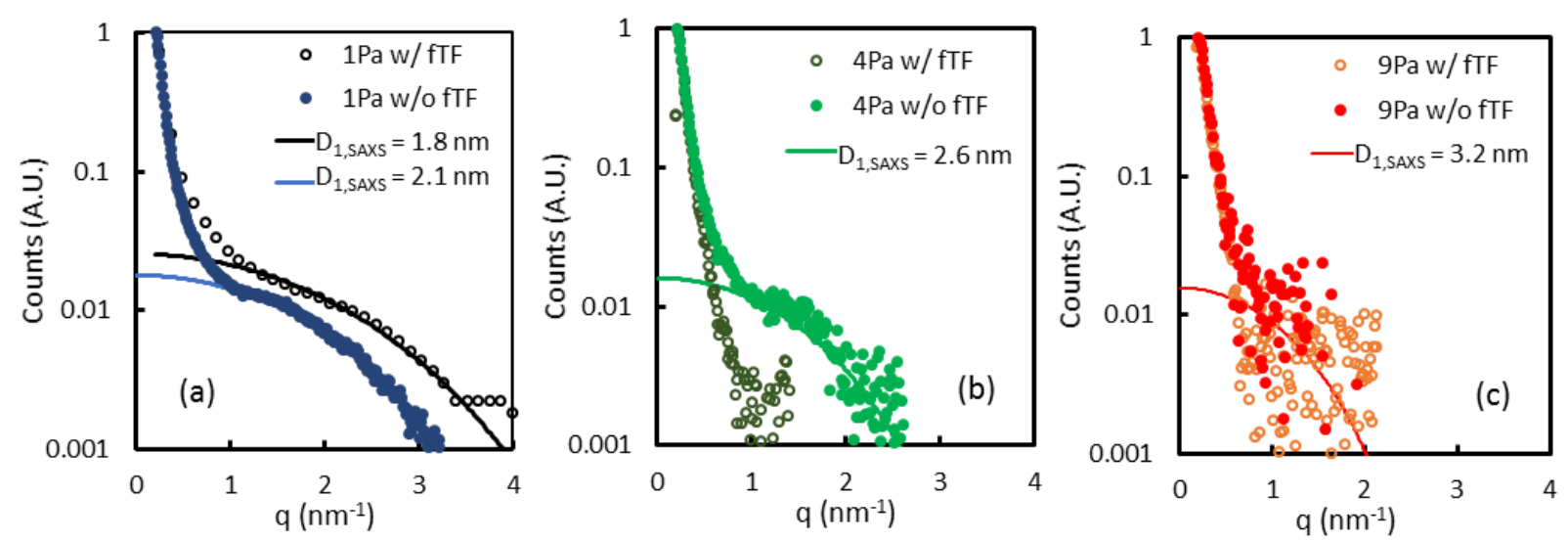

Figure 4. SAXS data and fitting curves for the samples prepared by plasma sputtering under different pressures: (a) $1.0 \mathrm{~Pa}$, (b) 4.0 and (c) $9.0 \mathrm{~Pa}$, with and without the floating thin film.

Fig. 5 shows the TEM images of Pt NPs supported on carbon black, namely $P t_{-} I P a \_w / \_T F$, $P t \_4 P a \_w / f T F$ and $P t \_9 P a \_w / f T F$. The corresponding size distributions are determined by analyzing about 100 to 150 individual Pt NPs on several TEM images with a diameter measured manually from digitized images. We only consider isolated nano-objects, and we assume that Pt-NPs are spherical in shape. The distributions appear bimodal, revealing the presence of two populations that are approximated by two Gaussian distribution functions (red and green lines). The first distributions displays average diameters $\left\langle D_{l, T E M}\right\rangle$ of $2.5,2.8$ and $3.7 \mathrm{~nm}$ with a standard deviation $\sigma$ of 0.5 and $0.6 \mathrm{~nm}(16<\sigma / \mathrm{R}<20 \%)$ for samples synthesized at pressures of 1.0, 4.0 and 9.0 $\mathrm{Pa}$ (red line), respectively, whereas the average diameter of the second distribution (green line) is characterized by a larger average diameter $\left\langle D_{2, T E M}\right\rangle$ comprised between 4.1 and 6.6 nm. TEM results confirm SAXS ones indicating an increase of the Pt NPs size with the argon pressure. The pressure rise induces the increase of the mean size $\left(\left\langle D_{1, T E M}\right\rangle\right)$ by a factor of 1.5 ; Wagener et al. ${ }^{43,44}$ reported an increasing factor (for the same pressure rise) of about 2 for Ag NPs synthesized on silicone oil. The $\left\langle D_{l, T E M}\right\rangle$ values are reported in Table 1 . SAXS results clearly reveal the presence of isolated nanoparticles with a mean diameter between 1.8 and $3.2 \mathrm{~nm}$ (depending on the pressure) and of nano-objects with bigger sizes. This second distribution observed on the TEM images could then correspond to these nano-objects of bigger sizes considering that the mean sizes determined by TEM (from ca. 4 to ca. $7 \mathrm{~nm}$ ) are close to those determined by SAXS (from ca. 5 to ca. $8 \mathrm{~nm}$ ), although slightly lower. These bigger 
objects could originate from the agglomeration of few individual NPs that we initially did not want to consider during the counting. This selection of nano-objects for the statistics can explain the lower size of these bigger nano-objects determined from TEM images than those determined by SAXS for population 2 where no selection of nano-objects is done. Although the comparison of results in term of mean particle size between SAXS patterns and TEM images is not straightforward due to the different preparation procedures (SAXS patterns are recorded on Pt NPs suspended in a glycerol/ethanol mixture, whereas TEM images are recorded on Pt NPs supported on Vulcan XC 72 carbon support obtained by mixture of the Pt NPs/glycerol suspension with the carbon support and filtration), the size of NPs and aggregates determined from both techniques are of the same order and display the same trends, respectively. The slightly lower sizes determined by SAXS than by TEM can be due to the dilution of the Pt NPs/glycerol suspension by ethanol that can lead to the dispersion of agglomerated Pt NPs (for example, ethanol is often used to disperse NPs for further deposition on a TEM grid for analysis). On Fig. 5c corresponding to nanoparticles formed under a pressure of 9.0 $\mathrm{Pa}$, the presence of agglomerates is clearly observed. These agglomerates are composed of individual nanoparticles ${ }^{45}$ that could have the same morphological property than those in population 1. According to SAXS measurements, the removal of the $f T F$ from the surface of glycerol results in the removal of all or part of the smaller Pt NPs, depending on the applied pressure. In the case of Pt NPs synthesized at 4.0 $\mathrm{Pa}$ and 9.0 $\mathrm{Pa}$, the removal of the $f T F$ leads to the complete disappearance of population 1. It is worth to note that the mean diameter of isolated Pt NPs in the $P t_{-} 1 P a \_w / f T F$ sample synthesized at a pressure of $1.0 \mathrm{~Pa}(1.8 \mathrm{~nm})$ is slightly smaller than the one obtained for the $P t \_l P a \_w / o \_f T F$ sample $(2.1$ $\mathrm{nm})$. This observation shows that a large proportion of Pt NPs in the floating thin film is probably composed of agglomerated NPs with a mean diameter smaller than the one for NPs dispersed in the liquid bulk, and therefore that a limited growth process continued to occur in the liquid bulk leading to bigger NPs. The small difference between the mean diameters for $P t_{-} I P a_{-} w / f T F$ sample and for $P t_{-} I P a_{-} w / \theta_{-} f T F$ sample seems to indicate that the NPs diluted in the bulk liquid could originate from the liquid-surface and that the growth in the liquid bulk is rather limited (even if the mean diameter increase to 2.1 nm probably due to the eollection of isolated Pt atoms). 


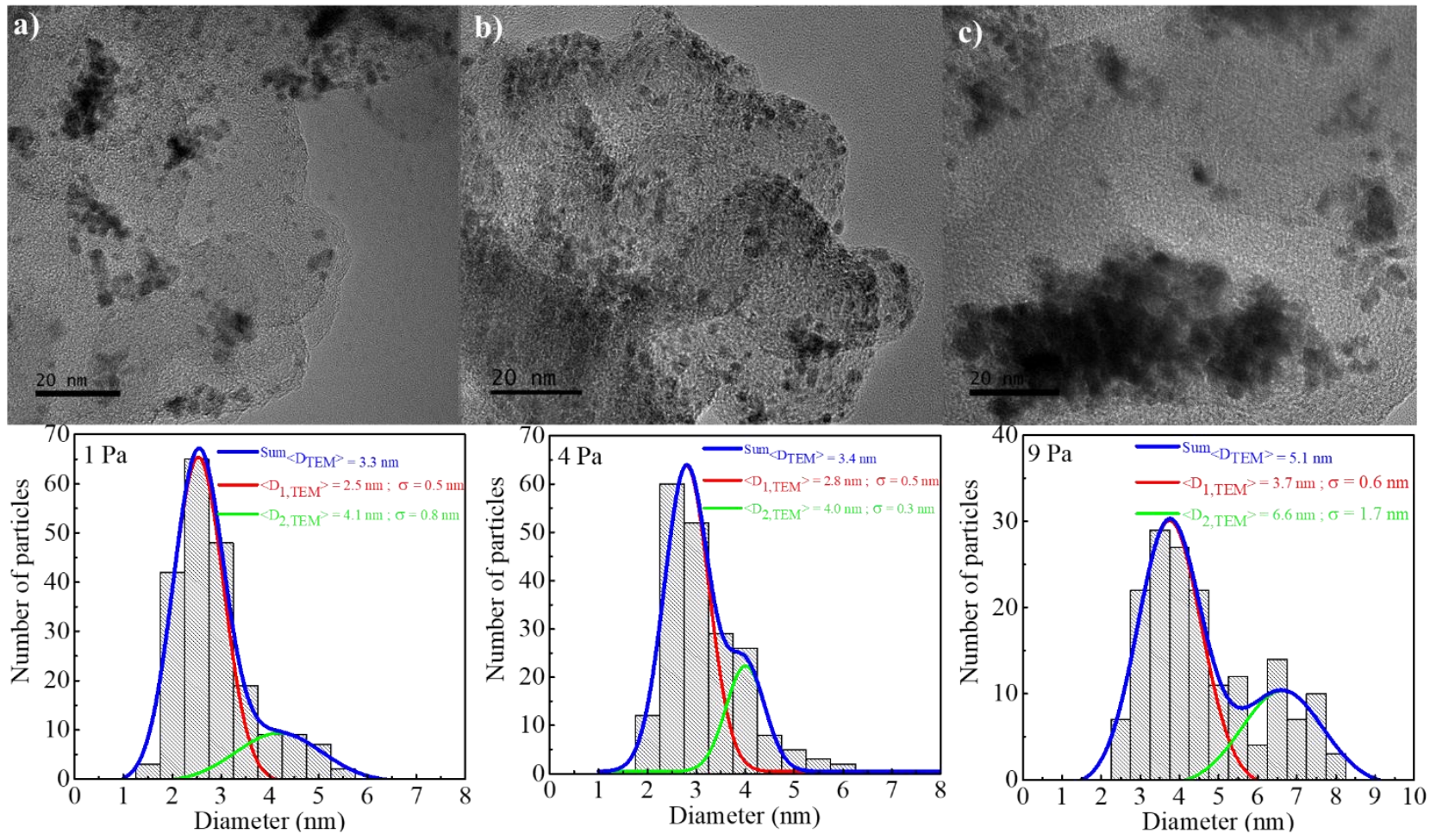

Figure 5. TEM images and corresponding size distributions of Pt NPs supported on carbon black synthesized for three samples: (a) $P t_{-} l P a \_w / \_f T$, (b) $P t \_4 P a_{-} w / \_f F$ and (c) $P t \_9 P a \_w / f T F$.

Table 1. List of 6 Pt-NPs samples with fitting data issued from SAXS, TEM and CV measurements.

\begin{tabular}{|c|c|c|c|c|}
\hline \multirow[b]{2}{*}{ Sample name } & \multirow{2}{*}{$\begin{array}{c}\text { SAXS } \\
\begin{array}{c}D_{1} \\
(\mathbf{n m})\end{array}\end{array}$} & \multirow{2}{*}{$\begin{array}{c}\text { TEM } \\
\begin{array}{c}<\mathrm{D}_{1, \mathrm{TEM}}> \\
(\mathbf{n m})\end{array}\end{array}$} & \multicolumn{2}{|c|}{$\mathrm{CV}$ measurements } \\
\hline & & & $\begin{array}{l}\text { ECSACv, oxide } \\
\left(\mathbf{m}^{2} \mathbf{g}^{-1}\right)\end{array}$ & $\begin{array}{c}\underset{\left(\mathbf{m}^{2} \mathbf{g}^{-1}\right)}{\operatorname{ECSA}} \mathbf{H}\end{array}$ \\
\hline$P t \_l P a \_w / \_f T F$ & 1.8 & 2.5 & 14.6 & 16.4 \\
\hline$P t \_l P a \_w / o \_f T F$ & 2.1 & - & 16.5 & 14.8 \\
\hline$P t \_4 P a \_w / f T F$ & - & 2.8 & 6.2 & 6.8 \\
\hline$P t \_4 P a \_w / o \_f T F$ & 2.6 & - & 14.4 & 15.8 \\
\hline$P t \_9 P a \_w / f T F$ & - & 3.7 & 5.0 & 4.8 \\
\hline$P t \_9 P a \_w / o \_f T F$ & 3.2 & - & 1.9 & 2.3 \\
\hline
\end{tabular}


Fig. 6 presents HRTEM micrographs of a Pt NPs supported on a larger sphere-like carbon particle. A zoom on this single Pt NP (Fig.6b) and the corresponding Fast Fourier Transform (FFT) pattern (Fig.6c) confirms the presence of (111) and (200) diffraction planes. (111) interplanar distances (average of $0.224 \pm 0.005$ $\mathrm{nm}$ ) are slightly lower than the $0.226 \mathrm{~nm}$ value corresponding to the Pt bulk face-centered cubic (fcc) phase. This could correspond to a shrinkage of the crystal lattice due to internal stress as it is observed for fcc clusters at the nanoscale due to high surface stress. ${ }^{46,47}$
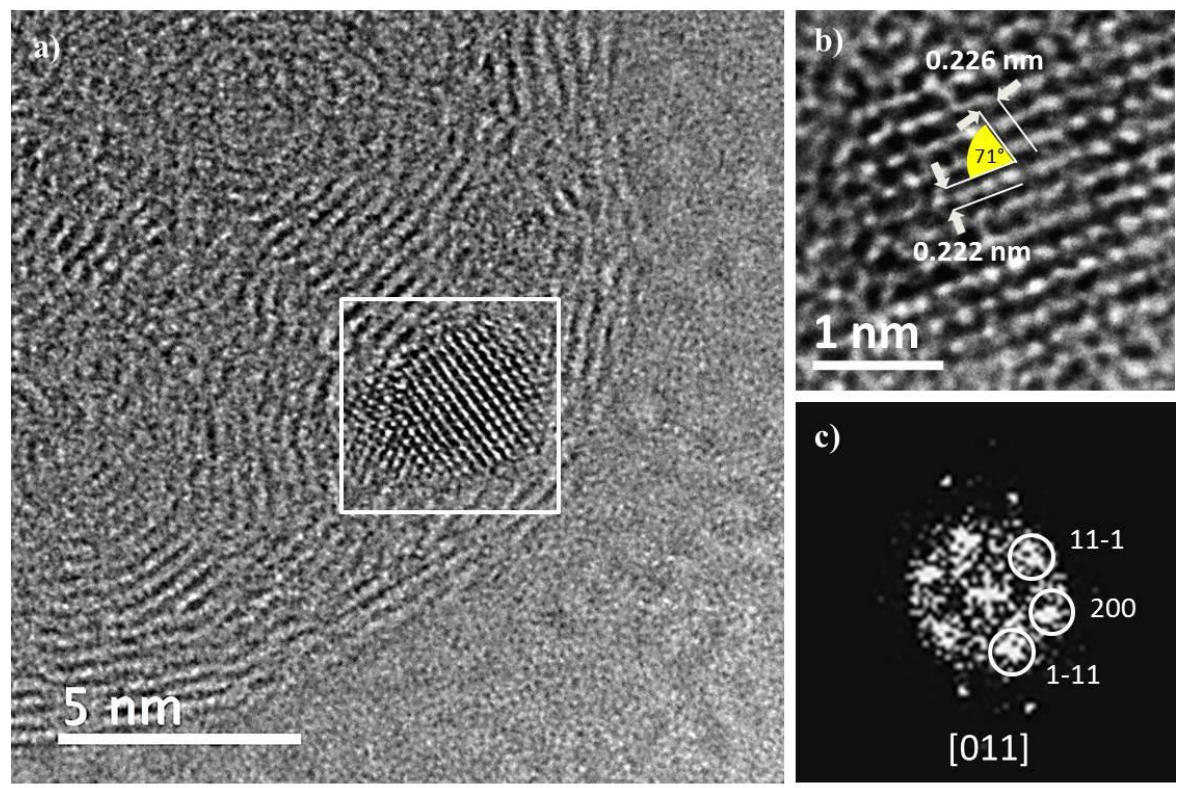

Figure 6. a) HRTEM micrographs of Pt NP supported on carbon grown at an argon pressure of $1 \mathrm{~Pa} . \mathrm{b}$ ) Zoom on the Pt NP at different focus (compared to a)) showing lattice planes distances corresponding to $\{111\}$ (resolution of $\pm 0.005 \mathrm{~nm}$ ), c) FFT of micrograph b) and the corresponding orientation of Pt NP near [011] zone axis.

Cyclic voltammograms of $\mathrm{Pt} \mathrm{NPs} / \mathrm{C}$ electrodes recorded in $\mathrm{N}_{2}$-purged $0.50 \mathrm{~mol} \mathrm{~L}^{-1} \mathrm{H}_{2} \mathrm{SO}_{4}$ electrolyte between $0.050 \mathrm{~V}$ and $1.450 \mathrm{~V}$ vs RHE are presented in Figure 7 . The signals for the underpotential adsorption of hydrogen and for its desorption from the platinum surface is visible between $0.050 \mathrm{~V}$ and $0.400 \mathrm{~V}$ vs RHE for all catalysts and are in agreement with other studies performed on Pt catalyst ${ }^{48,49}$. At higher potentials, from ca. $0.650 \mathrm{~V}$ vs. RHE, Pt surface atoms attract hydroxyl groups to form $\mathrm{Pt}-\mathrm{OH}_{\mathrm{ad}}$ species that are further oxidized to form $\mathrm{Pt}-\mathrm{O}_{\mathrm{ad}}$ surface oxides. In the negative-going scan, when decreasing 
the voltage, the oxidized Pt-O surface is reduced, leading to a reduction peak centered in the $0.700-0.750$ V vs. RHE potential range.

The electrochemically active surface area (ECSA) can give insights on the accessibility of Pt surface atoms in $\mathrm{Pt} / \mathrm{C}$ catalysts and further on the Pt electrocatalytic activity. The ECSA values can be calculated from the integration of the hydrogen desorption peak between 0.050 and $0.400 \mathrm{~V}$ (positive-going scan) or from the integration of the oxide reduction peak between 0.4 and $1 \mathrm{~V}$ (negative-going scan), after correction of the capacitive double layer contribution. Then, the peak integration gives the transferred charge for the reaction (knowing the scan rate) and the ECSA can be deduced from this charge assuming a specific charge of 210 $\mu \mathrm{C} . \mathrm{cm}^{-2}$ and $420 \mu \mathrm{C} . \mathrm{cm}^{-2}$ for the H-desorption peak (one-electron transfer) and the O-desorption peak (twoelectron transfer), respectively. ECSA results are reported in the Table 1. Both methods of ECSA determination give relatively close values for each catalyst. The ECSA for Pt NPs/C catalyst prepared at 9.0 Pa is noticeably low (inferior to $5 \mathrm{~m}^{2} \cdot \mathrm{g}^{-1}$ ) with the presence of the $f T F$ or not. This observation can be related to the morphological characterization of the $P t \_9 P a \_w / f T F$ sample by TEM showing the presence of very big agglomerates and of very few isolated nanoparticles (Fig. 5c), leading to a low electrochemically active surface area. Because the diffusion of platinum in the glycerol bulk is disfavored at high pressures, the amount of remaining platinum in the glycerol phase after removal of the floating thin film is very low, and its determination is likely associated with a very large uncertainty, as well as that of the ECSA. This problem was much less important for the other pressures because the amounts of platinum could be determined with a higher accuracy. The active surface area of the $P t \_4 P a \_w / f T F$ reaches values between 6.2 and $6.8 \mathrm{~m}^{2} . \mathrm{g}^{-}$ ${ }^{1}$, and that determined on $P t \_4 P a \_w / o \_f T F$ is improved between 14.4 and $15.8 \mathrm{~m}^{2} \cdot \mathrm{g}^{-1}$. The ECSA value for $P t \_P a \_w / o \_f T F\left(15.1 \mathrm{~m}^{2} \mathrm{~g}_{\mathrm{Pt}}{ }^{-1}\right.$ in average $)$ is very close to those determined for the $P t \_1 P a \_w / f T F(15.05$ $\mathrm{m}^{2} \mathrm{~g}_{\mathrm{Pt}^{-1}}$ in average) and $P t_{-} l P a_{-} w / o_{-} f T F\left(15.65 \mathrm{~m}^{2} \mathrm{~g}_{\mathrm{Pt}^{-1}}\right.$ in average $)$ catalysts. In the case of catalysts synthesized at $1.0 \mathrm{~Pa}$, the removal of the floating thin film has no effect on the active surface area, whereas its removal leads to dramatically increase of the ECSA for catalysts prepared at $4.0 \mathrm{~Pa}$. All these observations indicate that the increase of the synthesis pressure favors the formation of denser thin floating 
films at the glycerol surface with bigger stable agglomerates of Pt NPs that are further deposited on the carbon support.

But in the present study, the ECSA values are largely inferior to those obtained by Yoshii et al. ${ }^{18}$. These authors synthesized Pt NPs by plasma sputtering onto N,N,N-trimethyl-Npropylammoniumbis(trifluoromethesulfonyl)amide $\left(\left[\mathrm{N}_{1,1,1,3}\right]\left[\mathrm{Tf}_{2} \mathrm{~N}\right]\right)$, with a size of $2.8 \mathrm{~nm}$ and $3.7 \mathrm{~nm}$ similar to that of the Pt NPs synthesized in the present study (between 2.5 to $3.7 \mathrm{~nm}$ ) but obtained electrochemically active surface area of $44.3 \mathrm{~m}^{2} \cdot \mathrm{g}^{-1}$ and $63.1 \mathrm{~m}^{2} \cdot \mathrm{g}^{-1}$, respectively. The huge difference between the ECSA values determined on our Pt NPs and those reported by Yoshii et al ${ }^{18}$ could be linked to the agglomeration degree of our catalyst even after removal of the $f T F$, giving rise to the population 2 of nano-objects observed by SAXS that probably originated from the agglomeration of Pt NPs. The difference of deposition parameters and of the nature of liquid substrate can largely explain the discrepancy between both studies. ILs are known to form highly stable and uniformly dispersed NPs without the use of stabilizing agents due to their capacity to stabilize NPs through their constituent ions acting as surfactant. Although glycerol has a relative high surface coordination due to the presence of hydroxyl groups that are expected to promote the formation of NPs, it does not avoid the growth of a thin film. Moreover, MD simulation and deposition experiments clearly showed that Pt atoms only penetrate a shallow depth of the glycerol phase, leading inevitably to the formation of agglomerates. Stabilizing agents or surfactants could be necessary to favor faster diffusion of platinum in the glycerol bulk and to avoid the agglomeration process in the glycerol phase. Moreover, the glycerol used in the present study displays the high viscosity of ca. $0.60 \mathrm{~Pa} . \mathrm{s}$ at $25^{\circ} \mathrm{C}$ and atmospheric pressure, which is known to play an important role on the agglomeration process and NPs size. A high viscosity value leads to low diffusive velocities and thus induces the growth of larger particles and agglomerates, especially on the liquid surface ${ }^{50}$.

Here, lower active surface areas are obtained due to the presence of agglomerates. The decrease of viscosity leading to the formation of agglomerates in Pt plasma sputtering process lowering the ECSA, could be achieved by (i) using a water containing glycerol liquid mixture instead of pure glycerol, (ii) improving the 
energy flux transfer between the plasma and the liquid surface in order to heat the liquid surface and/or (iii) simply heating the liquid phase.

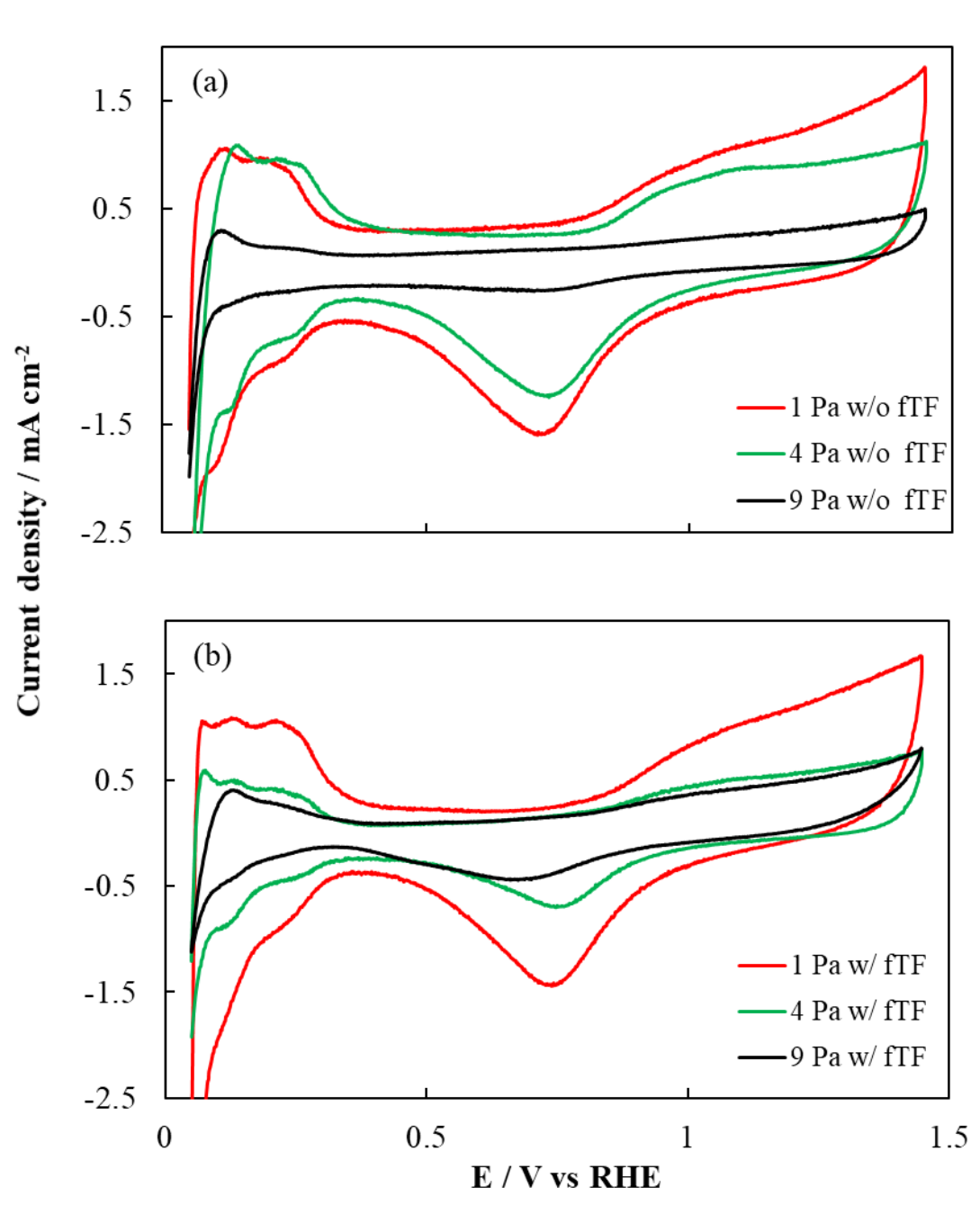

Figure 7. Cyclic voltammograms of Pt-NP catalysts without (a) and with (b) the floating thin film recorded in $\mathrm{N}_{2}$ purged $0.5 \mathrm{M} \mathrm{H}_{2} \mathrm{SO}_{4}$ electrolyte (between 0.1 and $1.45 \mathrm{~V}, \mathrm{~T}=20^{\circ} \mathrm{C}, \mathrm{v}=50 \mathrm{mV} / \mathrm{s}$ ).

\section{CONCLUSION}

Pt NPs have been synthesized by a plasma sputtering process directly onto glycerol as liquid substrate. It was shown that the argon pressure plays an important role on the NPs formation. Higher pressures (4.0 and 9.0 $\mathrm{Pa}$ ) induced the formation of a thin film on the glycerol surface while a lower pressure (1.0 Pa) led to 
the formation of a homogeneous dark suspension with a floating thin film. The MD simulations agreed with these experimental findings, which highlighted that the NPs diffusion in the liquid phase depends on the pressure and then on the associated kinetic energy of Pt atoms when arriving on the liquid surface.

SAXS measurements of as-deposited Pt NPs onto glycerol and TEM measurements on carbon-supported Pt NPs revealed an increase of the NPs size with the argon pressure, from 2.5 to $3.7 \mathrm{~nm}$ (TEM) when the argon pressure increased from 1.0 to $9.0 \mathrm{~Pa}$, and the existence of bimodal distributions. The nano-object population centred at higher mean sizes (population 2) corresponds likely to agglomerated NPs. Moreover, after the deposition of the Pt NPs on a carbon support, the materials synthesized at high pressure (9.0 Pa) formed big agglomerates and ramified NPs networks. It was also proposed that besides the pressure, the viscosity of the liquid phase also contributed to the formation of $f T F$ on the glycerol surface and Pt agglomerates.

This contribution shows therefore that the magnetron sputtering method is very powerful to synthesize nanoparticles with low particle sizes around $3 \mathrm{~nm}$, which is a convenient size for electrocatalytic reactions in low temperature fuel cells for example, and narrow size distribution. However, ECSAs were found to be very low and it was proposed that the level of Pt NPs agglomeration was responsible of these low values. To improve the dissemination of the Pt NPs on the carbon substrate for electrode preparation, it is proposed to investigate more suitable liquid phases, in terms of vapor pressure, viscosity, density, solubility, low boiling temperature, etc. This is of paramount importance for the development of such a clean synthesis method of nanostructured catalytic materials.

\section{Acknowledgements}

This work has been funded by Centre-Val de Loire French region in the frame of the Ambition for Research and Development (ARD) program named LAVOISIER 2 and by the CNRS project named PHYSNANOIL (PEPS INSIS program). Thanks to the MACLE Platform for the access to the JEOL ACCELARM 200F which was co-funded by the European Union and Centre-Val de Loire Region (FEDER). The authors thanks Eric Millon and Christophe Cachoncinlle for their contributions to the field of the deposits on the liquid 
substrate in the GREMI laboratory. We also thanks Stephanos Konstantinidis for the useful discussion about NPs and thin films synthesis in a liquid medium by magnetron sputtering. Finally, the authors thank Remi Lazzari for the IsGISAXS free software that we used to analyze the SAXS scattering signal. Finally, the authors acknowledge networking support from the International Research Network IRN Nanoalloys of CNRS.

\section{References}

(1) Fedotov, A. A.; Grigoriev, S. A.; Lyutikova, E. K.; Millet, P.; Fateev, V. N. Characterization of Carbon-Supported Platinum Nano-Particles Synthesized Using Magnetron Sputtering for Application in PEM Electrochemical Systems. Int. J. Hydrogen Energy 2013, 38 (1), 426-430. https://doi.org/10.1016/j.ijhydene.2012.09.121.

(2) Sui, S.; Wang, X.; Zhou, X.; Su, Y.; Riffat, S.; Liu, C. jun. A Comprehensive Review of Pt Electrocatalysts for the Oxygen Reduction Reaction: Nanostructure, Activity, Mechanism and Carbon Support in PEM Fuel Cells. J. Mater. Chem. A 2017, 5 (5), 1808-1825. https://doi.org/10.1039/C6TA08580F.

(3) Gewirth, A. A.; Thorum, M. S. Electroreduction of Dioxygen for Fuel-Cell Applications: Materials and Challenges. Inorg. Chem. 2010, 49 (8), 3557-3566. https://doi.org/10.1021/ic9022486.

(4) Wang, X.; Orikasa, Y.; Uchimoto, Y. Platinum-Based Electrocatalysts for the Oxygen-Reduction Reaction: Determining the Role of Pure Electronic Charge Transfer in Electrocatalysis. ACS Catal. 2016, 6 (7), 4195-4198. https://doi.org/10.1021/acscatal.6b00497.

(5) Brault, P.; Caillard, A.; Thomann, A. L.; Mathias, J.; Charles, C.; Boswell, R. W.; Escribano, S.; Durand, J.; Sauvage, T. Plasma Sputtering Deposition of Platinum into Porous Fuel Cell Electrodes. J. Phys. D. Appl. Phys. 2004, 37 (24), 3419-3423. https://doi.org/10.1088/0022-3727/37/24/010.

(6) Zhou, Z.; Zhou, W.; Wang, S.; Wang, G.; Jiang, L.; Li, H.; Sun, G.; Xin, Q. Preparation of Highly Active $40 \mathrm{Wt} . \%$ Pt/C Cathode Electrocatalysts for DMFC via Different Routes. In Catalysis Today; Elsevier, 2004; Vol. 93-95, pp 523-528. https://doi.org/10.1016/j.cattod.2004.06.121. 
Synthesized by Plasma-Chemical Reduction Method for Fuel Cell Applications. J. Electrochem. Soc. 2007, 154 (2), B165. https://doi.org/10.1149/1.2401032.

(8) Wender, H.; Migowski, P.; Feil, A. F.; Teixeira, S. R.; Dupont, J. Sputtering Deposition of Nanoparticles onto Liquid Substrates: Recent Advances and Future Trends. Coord. Chem. Rev. 2013, 257, 2468-2483. https://doi.org/10.1016/j.ccr.2013.01.013.

(9) Mougenot, M.; Caillard, A.; Brault, P.; Baranton, S.; Coutanceau, C. High Performance Plasma Sputtered PdPt Fuel Cell Electrodes with Ultra Low Loading. Int. J. Hydrogen Energy 2011, 36 (14), 8429-8434. https://doi.org/10.1016/j.ijhydene.2011.04.080.

(10) Cha, S. Y. Performance of Proton Exchange Membrane Fuel Cell Electrodes Prepared by Direct Deposition of Ultrathin Platinum on the Membrane Surface. J. Electrochem. Soc. 1999, 146 (11), 4055. https://doi.org/10.1149/1.1392591.

(11) Nguyen, M. T.; Yonezawa, T. Sputtering onto a Liquid: Interesting Physical Preparation Method for Multi-Metallic Nanoparticles. Sci. Technol. Adv. Mater. 2018, 19 (1), 883-898. https://doi.org/10.1080/14686996.2018.1542926.

(12) T. Tsuda, T. Kurihara, Y. Hoshino, T. Kiyama, K. Okazaki, T. Torimoto, and S. Kuwabata 77(8), 693 (2009)

(13) Paulechka, Y. U.; Kabo, G. J.; Blokhin, A. V.; Vydrov, O. A.; Magee, J. W.; Frenkel, M. Thermodynamic Properties of 1-Butyl-3-Methylimidazolium Hexafluorophosphate in the Ideal Gas State. J. Chem. Eng. Data 2003, 48 (3), 457-462. https://doi.org/10.1021/je025591i.

(14) Wender, H.; De Oliveira, L. F.; Feil, A. F.; Lissner, E.; Migowski, P.; Meneghetti, M. R.; Teixeira, S. R.; Dupont, J. Synthesis of Gold Nanoparticles in a Biocompatible Fluid from Sputtering Deposition onto Castor Oil. Chem. Commun. 2010, 46 (37), 7019-7021. https://doi.org/10.1039/c0cc01353f.

(15) Ndiaye, P. M.; Tavares, F. W.; Dalmolin, I.; Dariva, C.; Oliveira, D.; Oliveira, J. V. Vapor Pressure Data of Soybean Oil, Castor Oil, and Their Fatty Acid Ethyl Ester Derivatives. J. Chem. Eng. 
Data 2005, 50 (2), 330-333. https://doi.org/10.1021/je049898o.

(16) Wender, H.; Gonçalves, R. V.; Feil, A. F.; Migowski, P.; Poletto, F. S.; Pohlmann, A. R.; Dupont, J.; Teixeira, S. R. Sputtering onto Liquids: From Thin Films to Nanoparticles. J. Phys. Chem. C 2011, 115 (33), 16362-16367. https://doi.org/10.1021/jp205390d.

(17) Hatakeyama, Y.; Onishi, K.; Nishikawa, K. Effects of Sputtering Conditions on Formation of Gold Nanoparticles in Sputter Deposition Technique. RSC Adv. 2011, 1 (9), 1815-1821. https://doi.org/10.1039/c1ra00688f.

(18) Yoshii, K.; Yamaji, K.; Tsuda, T.; Matsumoto, H.; Sato, T.; Izumi, R.; Torimoto, T.; Kuwabata, S. Highly Durable Pt Nanoparticle-Supported Carbon Catalysts for the Oxygen Reduction Reaction Tailored by Using an Ionic Liquid Thin Layer. J. Mater. Chem. A Mater. energy Sustain. 2016, 4, 12152-12157. https://doi.org/10.1039/C6TA04859E.

(19) Tsuda, T.; Yoshii, K.; Torimoto, T.; Kuwabata, S. Oxygen Reduction Catalytic Ability of Platinum Nanoparticles Prepared by Room-Temperature Ionic Liquid-Sputtering Method. J. Power Sources 2010, 195 (18), 5980-5985. https://doi.org/10.1016/j.jpowsour.2009.11.027.

(20) K. Yoshii, T. Tsuda, T. Arimura, A. Imanishi, T. Torimoto, and S. Kuwabata, Platinum nanoparticle immobilization onto carbon nanotubes using Pt-sputtered room-temperature ionic liquid, $R S C A d v .2012,2$, 8262. https://doi.org/10.1039/c2ra21243a

(21) I.Y. Cha, M. Ahn, S.J. Yoo, and Y.E. Sung, Facile synthesis of carbon supported metal nanoparticles via sputtering onto a liquid substrate and their electrochemical application, RSC Adv. 2014, 4, 38575. https://doi.org/10.1039/c4ra05213g

(22) L. Deng, M.T. Nguyen, and T. Yonezawa, Sub-2 nm Single-Crystal Pt Nanoparticles via Sputtering onto a Liquid Polymer, Langmuir 2018, 34, 2876. https://doi.org/10.1021/acs.langmuir.7b04274

(23) I.Y. Cha, H.T. Kim, M. Ahn, J.H. Jang, Y.G. Kim, Y.E. Sung, and S.J. Yoo, Synthesis and growth mechanism of carbon-supported nanoparticle catalysts by physical vapor deposition onto a liquid medium substrate, Appl. Surf. Sci. 2019, 471, 1083. https://doi.org/10.1016/j.apsusc.2018.12.144

(24) Glycerine Producers' Association. Physical Properties of Glycerine and Its Solutions; 1963. 
Graves, D. B.; Brault, P. Molecular Dynamics for Low Temperature Plasma-Surface Interaction Studies. J. Phys. D. Appl. Phys. 2009, 42 (19), 194011. https://doi.org/10.1088/0022-3727/42/19/194011.

(26) Neyts, E. C.; Brault, P. Molecular Dynamics Simulations for Plasma-Surface Interactions. Plasma Process. Polym. 2017, 14 (1-2), 1-18. https://doi.org/10.1002/ppap.201600145.

(27) Liang, T.; Shin, Y. K.; Cheng, Y.-T.; Yilmaz, D. E.; Vishnu, K. G.; Verners, O.; Zou, C.; Phillpot, S. R.; Sinnott, S. B.; van Duin, A. C. T. Reactive Potentials for Advanced Atomistic Simulations. Annu. Rev. Mater. Res. 2013, 43 (1), 109-129. https://doi.org/10.1146/annurev-matsci-071312-121610.

(28) Senftle, T. P.; Hong, S.; Islam, M. M.; Kylasa, S. B.; Zheng, Y.; Shin, Y. K.; Junkermeier, C.; Engel-Herbert, R.; Janik, M. J.; Aktulga, H. M.; Verstraelen, T.; Grama, A.; Van Duin, A. C. T. The ReaxFF Reactive Force-Field: Development, Applications and Future Directions. npj Computational Materials. Nature Publishing Group March 4, 2016, pp 1-14. https://doi.org/10.1038/npjcompumats.2015.11.

(29) Xie, L.; Brault, P.; Bauchire, J. M.; Thomann, A. L.; Bedra, L. Molecular Dynamics Simulations of Clusters and Thin Film Growth in the Context of Plasma Sputtering Deposition. J. Phys. D. Appl. Phys. 2014, 47 (22), 224004. https://doi.org/10.1088/0022-3727/47/22/224004.

(30) Brault, P.; Neyts, E. C. Molecular Dynamics Simulations of Supported Metal Nanocatalyst Formation by Plasma Sputtering. Catal. Today 2015, 256, 3-12. https://doi.org/10.1016/j.cattod.2015.02.004.

(31) Shin, Y. K.; Gai, L.; Raman, S.; Van Duin, A. C. T. Development of a ReaxFF Reactive Force Field for the Pt-Ni Alloy Catalyst. J. Phys. Chem. A 2016, 120 (41), 8044-8055. https://doi.org/10.1021/acs.jpca.6b06770.

(32) Glatter, O.; Kratky, O. General Theory X- Ray Scattering. Small-Angle X-ray Scatt. 1982, 36 (5), 17-51. https://doi.org/10.1002/actp.1985.010360520.

(33) Th.Zemb; P.Lindner. Neutron, X-Rays and Light. Scattering Methods Applied to Soft Condesed Matter; Amsterdam ; Boston : Elsevier, Ed.; North-Holland delta series, 2002.

(34) Andreazza, P. Probing Nanoalloy Structure and Morphology. In Nanoalloys: Synthesis, Structure 
and Properties; D. Alloyeau, C. Ricolleau, C. Mottet, Eds.; Springer-Verlag: London, 2012; pp 69-114. (35) Raghuwanshi, S.V.; Ochmann, M.; Hoell, A.; Polzer, F.; Rademann, K.; Deep Eutectic Solvents for the Self-Assembly of Gold Nanoparticles: A SAXS, UV-Vis, and TEM Investigation, Langmuir 2014, 30, 6038-6046. 10.1021/la500979p].

(36) Seung Han Lee, Hyun Kyu Jung, Tae Cheol Kim, Chang Hee Kim, Chang Hwan Shin, Tae-Sik Yoon, A-Ra Hong, Ho Seong Jang, Dong Hun Kim, Facile method for the synthesis of gold nanoparticles using an ion coater, Applied Surface Science 2018, 434, 1001-1006. https://doi.org/10.1016/j.apsusc.2017.11.008. (37) Hatakeyama, Y.; Morita, T.; Takahashi, S.; Onishi, K.; and Nishikawa, K.; Synthesis of Gold Nanoparticles in Liquid Polyethylene Glycol by Sputter Deposition and Temperature Effects on their Size and Shape, J. Phys. Chem. C 2011, 115, 3279-3285. 10.1021/jp110455k.

(38) Steinfeldt, N.; In Situ Monitoring of Pt Nanoparticle Formation in Ethylene Glycol Solution by SAXSInfluence of the $\mathrm{NaOH}$ to Pt Ratio, Langmuir 2012, 28, 13072-13079. dx.doi.org/10.1021/1a3026232.

(39) Hatakeyama, Y.; Takahashi, S.; Nishikawa, K.; Can Temperature Control the Size of Au Nanoparticles Prepared in Ionic Liquids by the Sputter Deposition Technique? J. Phys. Chem. C 2010, 114, 11098-11102. $10.1021 / \mathrm{jp} 102763 \mathrm{n}$.

(40) Hatakeyama, Y.; Judai, K.; Onishi, K.; Takahashi, S.; Kimura S.; Nishikawa, K.; Anion and cation effects on the size control of Au nanoparticles prepared by sputter deposition in imidazolium-based ionic liquids, Phys.Chem.Chem.Phys., 2016, 18, 2339.

(41) Dirk Wartel. Primary Particles - Agglomerates - Aggregates. In Nanomaterials; Wiley-VCH Verlag GmbH \& Co. KGaA: Weinheim, Germany, 2013; pp 9-25.

(42) Alexeeva, O. K.; Fateev, V. N. Application of the Magnetron Sputtering for Nanostructured Electrocatalysts Synthesis. Int. J. Hydrogen Energy 2016, $41 \quad$ (5), 3373-3386. https://doi.org/10.1016/j.ijhydene.2015.12.147.

(43) Wagener, M.; Murty, B.S.; Günther, B.; in Nanocrystalline and Nanocomposite Materials II, edited by Komarnenl, S.; Parker, J. C; Wollenberger H. J. (Materials Research Society, Pittsburgh PA, 1997), Vol. 457, pp. 149-154. https://doi.org/10.1557/PROC-457-149 
(44) Wagener, M.; Günther, B.; Sputtering on liquids - a versatile process for the production of magnetic suspensions? Journal of Magnetism and Magnetic Materials 1999, 201, 41-44. https://doi.org/10.1016/S0304-8853(99)00055-4.

(45) Keene, A. M.; Tyner, K. M. Analytical Characterization of Gold Nanoparticle Primary Particles, Aggregates, Agglomerates, and Agglomerated Aggregates. J. Nanoparticle Res. 2011, 13 (8), 3465-3481. https://doi.org/10.1007/s11051-011-0268-4.

(46) Nafday, D.; Sarkar, S.; Ayyub, P.; Saha-Dasgupta, T. A Reduction in Particle Size Generally Causes Body-Centered-Cubic Metals to Expand but Face-Centered-Cubic Metals to Contract. ACS Nano 2018, 12 (7), 7246-7252. https://doi.org/10.1021/acsnano.8b03360.

(47) Wasserman, H. J.; Vermaak, J. S. On the Determination of the Surface Stress of Copper and Platinum. Surf. Sci. 1972, 32 (1), 168-174. https://doi.org/10.1016/0039-6028(72)90127-6.

(48) Kongkanand, A.; Vinodgopal, K.; Kuwabata, S.; Kamat, P. V. Highly Dispersed Pt Catalysts on Single-Walled Carbon Nanotubes and Their Role in Methanol Oxidation. J. Phys. Chem. B 2006, 110 (33), 16185-16188. https://doi.org/10.1021/jp064054s.

(49) Li, Y.; Li, Y.; Zhu, E.; McLouth, T.; Chiu, C. Y.; Huang, X.; Huang, Y. Stabilization of HighPerformance Oxygen Reduction Reaction Pt Electrocatalyst Supported on Reduced Graphene Oxide/carbon Black Composite. J. Am. Chem. Soc. 2012, 134 (30), 12326-12329. https://doi.org/10.1021/ja3031449.

(50) Staszek, M.; Siegel, J.; Polívková, M.; Švorčík, V. Influence of Temperature on Silver Nanoparticle Size Prepared by Sputtering into PVP-Glycerol System. Mater. Lett. 2017, 186, 341-344. https://doi.org/10.1016/j.matlet.2016.10.036. 